\title{
ANAPLASMOSE CONGÊNITA EM BEZERRA (Bos indicus) DA RAÇA NELORE RELATO DE CASO
}

\author{
GIRARDI, Annita Morais ${ }^{1}$ \\ TOLEDO, Carmen Zilda Pereira de ${ }^{2}$ \\ LACERDA NETO, José Corrêa de $\mathrm{de}^{3}$ \\ TONIOLLO, Gilson Hélio ${ }^{4}$ \\ BARREIRO, Fabiana Ribeiro
}

\begin{abstract}
RESUMO: Descreve-se um caso de anaplasmose congênita em uma bezerra da raça Nelore nascida no município de Orlândia, São Paulo. O animal apresentava, desde o nascimento, extrema apatia, decúbito lateral permanente, desidratação, inapetência e icterícia. A mãe da bezerra apresentou emagrecimento importante durante a gestação. $\mathrm{O}$ resultado do hematócrito, realizado no laboratório da propriedade, indicou anemia. O animal veio a óbito quatro dias após seu nascimento e, à necropsia, apresentou icterícia severa generalizada, carcaça desidratada, hepatomegalia e pulmões com áreas de consolidação, de consistência carnosa, principalmente na parte ventral dos lobos pulmonares. O exame do esfregaço sanguíneo revelou que $70 \%$ das hemácias da bezerra estavam parasitadas pelo Anaplasma marginale. Considerando-se a sintomatologia e os achados necroscópicos, a elevada parasitemia apresentada, o prolongado período de incubação do agente e o emagrecimento da vaca gestante, possivelmente devido à manifestação aguda da doença, conclui-se que este foi um caso de transmissão transplacentária de Anaplasma marginale.
\end{abstract}

Palavras-chave: Anaplasmose. Bovino. Infecção congenital.

\section{CONGENITAL ANAPLASMOSIS IN A NELLORE CALF (Bos indicus) - CASE REPORT}

SUMMARY: A case of congenital anaplasmosis in a Nellore calf was observed at Orlândia, São Paulo, Brazil. Since the birth, the animal presented intense aphaty, permanent lateral decubitus, dehydration, inappetence, and icterus. The cow, mother of this calf, presented weight loss during the pregnancy. The hematocrit was done at the farm laboratory and indicated anemia. The animal had died after four days from its birth. The necropsy evidenced generalized severe icterus, dehydrated carcass, liver enlargement, and pulmonary consolidation mainly in the ventral area of the lung lobes. The blood smear test showed that $70 \%$ of the erythrocytes were parasitized by Anaplasma marginale. The clinical signs, the necropsy, the great parasitemia, the long parasite incubation period, and the weight loss of the cow during the pregnancy, possibly caused by an acute manifestation of the disease, suggest that it was a case of Anaplasma marginale transplacental transmission.

Keywords: Anaplasmosis. Bovine. Congenital infection.

\section{INTRODUÇÃO}

A anaplasmose é uma doença que acomete os ruminantes causada pelo Anaplasma spp., pertencente à ordem Rickettsiales. Nos bovinos, o Anaplasma marginale é o principal agente etiológico da doença (RADOSTITS et al., 2007). A anaplasmose bovina ocorre em regiões tropicais e subtropicais (AUBRY e

\footnotetext{
${ }^{1}$ Doutoranda em Clínica Médica Veterinária, Faculdade de Ciências Agrárias e Veterinárias - UNESP Jaboticabal.

${ }^{2}$ Doutoranda em Cirurgia Veterinária, Faculdade de Ciências Agrárias e Veterinárias - UNESP Jaboticabal.

${ }^{3}$ Professor adjunto, Departamento de Clínica e Cirurgia Veterinária, Faculdade de Ciências Agrárias e Veterinárias - UNESP Jaboticabal.

${ }^{4}$ Professor titular, Departamento de Medicina Veterinária Preventiva e Reprodução Animal, Faculdade de Ciências Agrárias e Veterinárias - UNESP Jaboticabal.

${ }^{5}$ Doutoranda em Medicina Veterinária Preventiva, Faculdade de Ciências Agrárias e Veterinárias - UNESP Jaboticabal.
} 
GEALE, 2011) e a severidade da doença aumenta com a idade do animal (RADOSTITS et al., 2007; AUBRY e GEALE, 2011). O agente é disseminado por vetores como os carrapatos da família Ixodidae, os dípteros dos gêneros Tabanus e Stomoxys ou por fômites. Após um período de incubação de sete a 60 dias (KOCAN et al., 2003), o Anaplasma marginale invade os eritrócitos e inicia ciclos de replicação, remoção das células infectados pelo sistema reticuloendotelial e subsequente invasão de novos eritrócitos (RADOSTITS et al., 2007; AUBRY e GEALE, 2011), causando anemia, icterícia e liberação de mediadores inflamatórios de fase aguda, com consequente aparecimento de febre. $\mathrm{O}$ agente pode ser identificado na periferia de até $10 \%$ dos eritrócitos nos casos subagudos e em mais de $50 \%$ nos superagudos. Os animais que resistem à infecção se tornam portadores e sua exposição a influências desvitalizantes pode resultar na forma aguda da doença (RADOSTITS et al., 2007). A anaplasmose bovina causa importante perda econômica pela redução no ganho de peso e na produção de leite, abortos, custos do tratamento e mortalidade (KOCAN et al., 2003; RADOSTITS et al., 2007).

A transmissão do Anaplasma marginale tem sido motivo de controvérsia em relação aos seus meios, mecanismos e à importância epidemiológica dos vetores (KESSLER, 2001). A infecção transplacentária ocorre menos frequentemente a campo do que experimentalmente, resultando em aborto ou infecção neonatal (RADOSTITS et al., 2007) e contribuindo, possivelmente, para a epidemiologia da anaplasmose bovina em algumas regiões (POTGIETER e VAN RENSBURG, 1987; KOCAN et al., 2003). A produção de bezerros infectados assintomáticos torna esta forma de transmissão importante na manutenção deste organismo e pode ser um evento frequente, melhor detectado com técnicas biotecnológicas recentes como a reação em cadeia de polimerase - PCR (AÑEZ-ROJAS et al., 2010). Os mecanismos desta transmissão não estão esclarecidos, embora provavelmente ocorra por uma fase ativa extra-eritrocitária do microrganismo, já que as hemácias não passam através da placenta bovina (FOWLER \& SWIFT, 1975; ZAUGG, 1985). O aborto está relacionado à anemia das vacas com anaplasmose, levando à hipóxia do feto, a qual se agrava no último terço da gestação, quando a demanda fetal de oxigênio é maior (SWIFT e PAUMER, 1978).

São poucos os relatos sobre a ocorrência de infecção congênita natural da anaplasmose bovina, a maioria descrevendo quadros de apatia, decúbito, desidratação, anemia, icterícia e problemas respiratórios. Wandera \& Munyua (1971) e Bird (1973) reportaram casos em bezerros neonatos, embora as matrizes não tenham desenvolvido sinais clínicos durante a gestação. Paine e Miller (1977) acompanharam um bezerro que veio a óbito aos seis dias de idade, com sete a $8 \%$ de hemácias infectadas pelo Anaplasma marginale. Correa et al. (1978) observaram, na necropsia de três fetos parasitados pelo agente, abortados entre sete e nove meses de gestação, hepatomegalia, petéquias, baço aumentado e congesto e lóbulos pulmonares hemorrágicos. Passos e Lima (1984) diagnosticaram a infecção vertical em bezerro de dois dias de idade, com parasitemia de $15 \%$ e esplenomegalia. Benesi et al. (1999) descreveram a ocorrência em um bezerro de sete dias de idade, o qual apresentou 20\% das hemácias parasitadas. Gonçalves et al. (2005) reportaram um caso em bezerro de um dia de idade no qual, à necropsia, observou-se icterícia, hemorragias, hepatoesplenomegalia, congestão e edema cerebral, petéquias na serosa do abomaso e presença de Anaplasma spp. no tecido esplênico. Laus et al. (2006) relataram o caso de um bezerro de aproximadamente seis horas de vida com febre, apatia, inapetência, hemácias parasitadas por Anaplasma marginale e uveíte causada pela infecção transplacentária do agente. Pypers et al. (2011) descreveram a ocorrência em uma bezerra de dois dias de idade, com quadro clínico e achados necroscópicos correspondentes à anaplasmose congênita e coinfectada pelo agente da diarréia bovina a vírus (BVDV), sugerindo que a resistência ao tratamento com oxitetraciclina e a gravidade incomum da anaplasmose em um animal jovem devem-se à supressão da imunidade mediada por células causada pela coinfecção do BVDV.

Nucleus Animalium, v.4, n.1, maio 2012 
A transmissão transplacentária tem sido relacionada à ocorrência da forma aguda na matriz durante a prenhez, principalmente no terço final de gestação. Trueblood et al. (1971) infectaram um feto bovino por inoculação de sangue infectado, in utero, na cavidade peritoneal do mesmo, aos 100 dias de gestação. Fowler e Swift (1975) observaram abortos, morte fetal e o nascimento de um bezerro saudável portador do agente ao infectarem vacas no último trimestre de gestação. Swift e Paumer (1976), ao inocular vacas no último terço da gestação, induziram nestas a fase clínica da anaplasmose e a transmissão transplacentária em 40\% dos animais. Zaugg e Kuttler (1984) constataram a transmissão in utero em animais afetados com anaplasmose aguda após 190 dias de gestação. Zaugg (1985) verificou que a infecção transplacentária em bovinos ocorre no segundo e terceiro terços da gestação, ao inocular Anaplasma marginale em vacas e obter o sangue dos fetos em vários estágios de desenvolvimento. Salabarria e Pino (1988) detectaram a anaplasmose em 32 de 37 bezerros nascidos de vacas afetadas pela doença clínica nos dois últimos terços da gestação. Ribeiro et al. (1995) inocularam o Anaplasma marginale em 11 vacas, 60 a 24 dias antes do parto, provocando a fase clínica da doença e a passagem vertical do agente em $36 \%$ dos animais.

Entretanto, outros estudos sugerem que a transmissão transplacentária pode ocorrer em vacas portadoras crônicas (KESSLER, 2001; GRAU, 2006). Norton et al. (1983) descreveram um caso de bezerro nascido de matriz imunizada, originária de área endêmica para Boophilus microplus, introduzida com 10 semanas de gestação em área livre de carrapatos, sem sinais clínicos de anaplasmose durante a prenhez. Potgieter e Van Rensburg (1987) diagnosticaram 12,5\% de transmissão transplacentária em matrizes cronicamente infectadas. Valeirón et al. (2003) observaram que todos os bezerros das vacas portadoras de Anaplasma marginale analisadas apresentaram parasitemia aos 30 dias de idade. AñezRojas et al. (2010) detectaram, por PCR de amostras de sangue, que 40\% dos bezerros de vacas portadoras assintomáticas de Anaplasma marginale possuíam DNA específico do agente.

\section{RELATO DE CASO}

A bezerra Nelore, nascida no dia 10 de agosto de 2009, no município de Orlândia - SP, foi encontrada em decúbito lateral, apática, com hipotermia e sem conseguir se manter em estação, porém com peso e tamanho normais para os neonatos da raça. No primeiro dia de vida, apresentava-se com leve icterícia e desidratada. Administrou-se soro glicofisiológico a 5\% intravenosamente e alimentação através de mamadeira, primeiramente com colostro e depois com leite, com baixa ingestão. A mãe apresentou emagrecimento importante durante a gestação. No segundo e terceiro dias de vida, o animal tornou-se mais debilitado, desidratado (figura 1) e com icterícia severa, visível nas mucosas oral, ocular e vaginal (figura 2). Além disso, observou-se respiração profunda e ruidosa, corrimento nasal seroso e sinais de afecção neurológica. Realizou-se fluidoterapia endovenosa com solução fisiológica $0,9 \%$ e glicofisiológica a 5\%, transfusão sanguínea e administrou-se tetraciclina de longa ação, na dose de 20 $\mathrm{mg} / \mathrm{kg}$, por via intramuscular.

\section{RESULTADOS E DISCUSSÃO}

O hematócrito, realizado no laboratório da propriedade, resultou em $35 \%$ e, apesar de estar dentro dos limites normais, foi considerado baixo dado o elevado grau de desidratação do animal, entre oito e 10\%. A bezerra veio a óbito quatro dias após seu nascimento. À necropsia, observou-se icterícia severa generalizada, carcaça desidratada, hepatomegalia e áreas de consolidação de consistência carnosa principalmente na parte ventral dos lobos pulmonares (figuras 3 e 4). A análise do esfregaço sanguíneo, realizada no Laboratório de Patologia Clínica "Prof. Dr. Joaquim Martins Ferreira Neto", do Hospital 
Veterinário "Governador Laudo Natel", na Faculdade de Ciências Agrárias e Veterinárias - Unesp Campus de Jaboticabal, revelou que $70 \%$ das hemácias do animal estavam parasitadas pelo Anaplasma marginale.

FIGURA 1 - Realização de fluidoterapia em bezerra Nelore, aos dois dias de idade, a qual se apresentava desidratada, apática e em decúbito lateral permanente

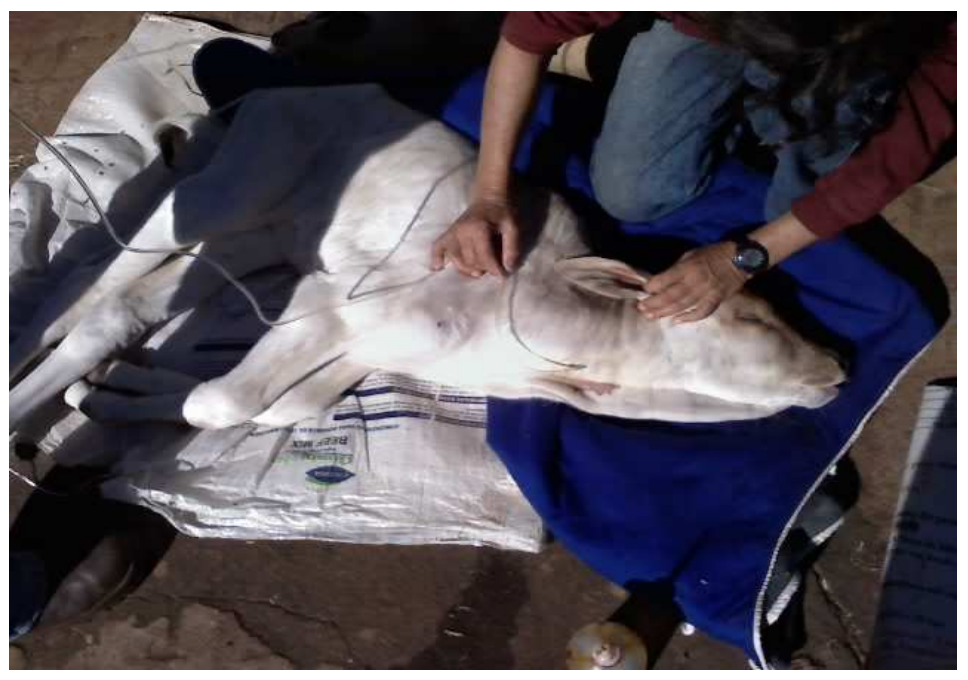

FIGURA 2 - Esclera ocular (A), mucosas oral (B) e vaginal (C) de bezerra Nelore com dois dias de idade, apresentando icterícia severa.
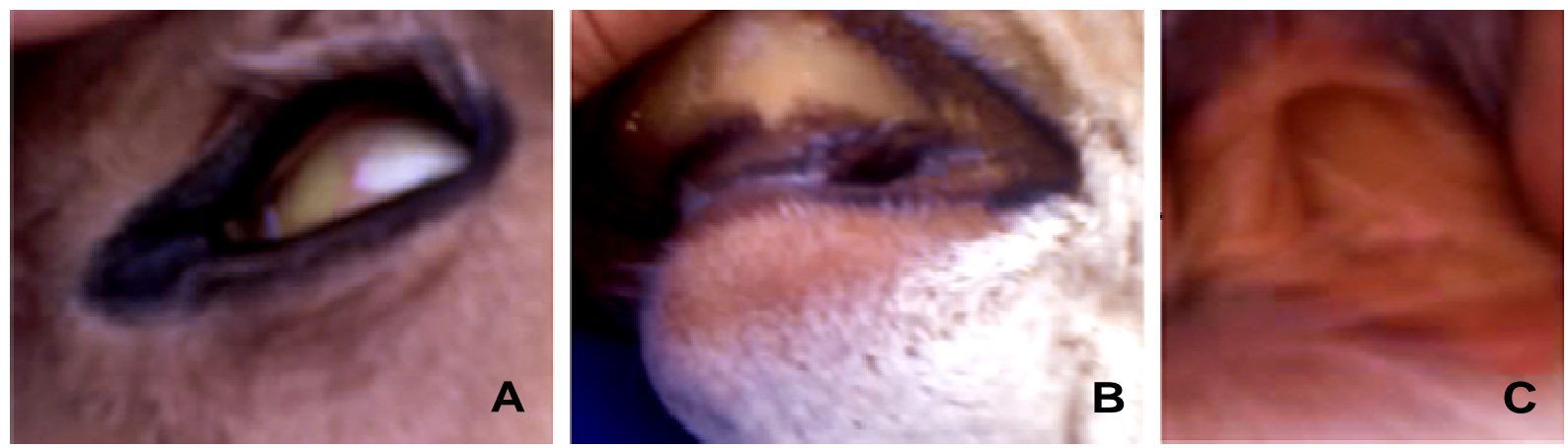

FIGURA 3 - Necropsia de bezerra Nelore, a qual veio a óbito 4 dias após o nascimento, em que se observa áreas de consolidação pulmonar de aspecto hemorrágico e consistência carnosa, além de icterícia generalizada da carcaça.

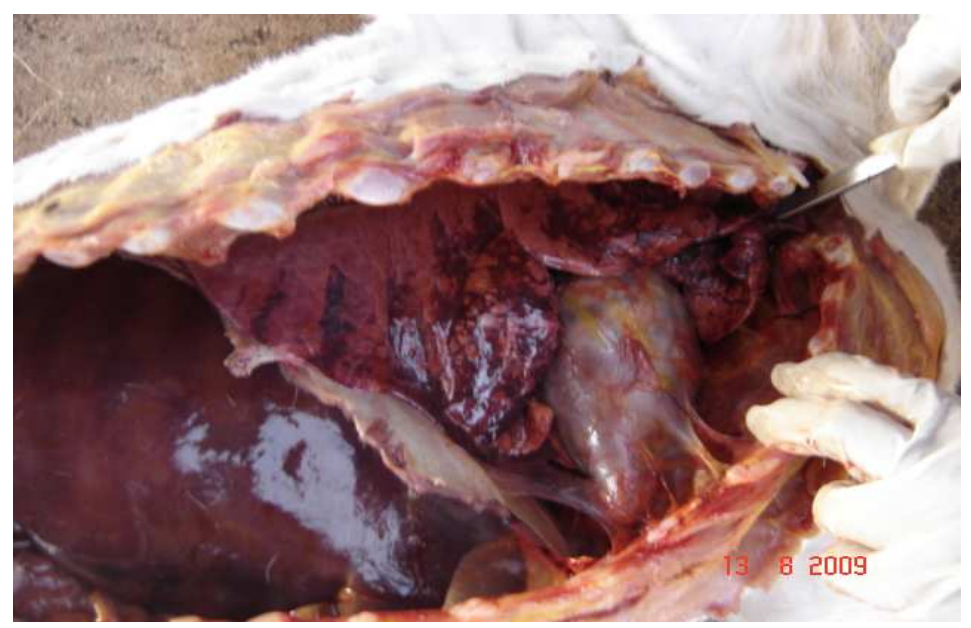


FIGURA 4 - Necropsia de bezerra Nelore, a qual veio a óbito 4 dias após o nascimento, em que se observa hepatomegalia e icterícia generalizada da carcaça.

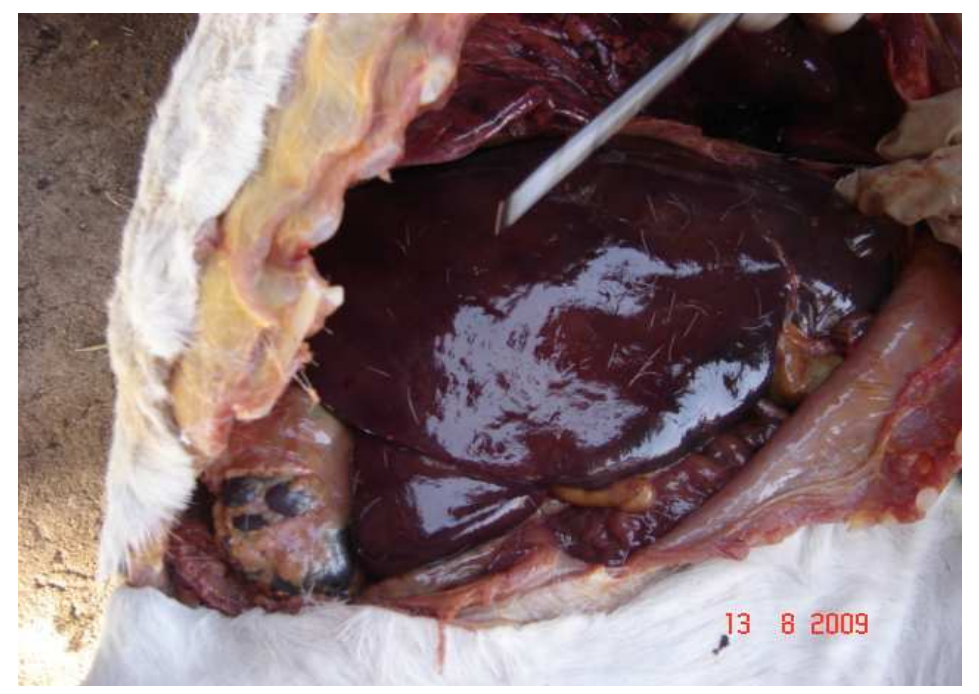

A sintomatologia e os achados necroscópicos observados assemelham-se aos descritos por Paine e Miller (1977), Correa et al. (1978), Norton et al. (1983), Passos e Lima (1984), Benesi et al. (1999), Gonçalves et al. (2005), Laus et al. (2006) e Pypers et al. (2011). Considerando-se o prolongado período de incubação do agente, entre duas e cinco semanas (RADOSTITS et al., 2007), a elevada parasitemia apresentada pelo animal e o emagrecimento da vaca gestante, possivelmente devido a uma manifestação aguda da doença, um dos principais fatores para a ocorrência da infecção pré-natal da anaplasmose bovina (TRUEBLOOD et al., 1971; FOWLER e SWIFT, 1975; SWIFT e PAUMER, 1976; ZAUGG e KUTTLER, 1984; ZAUGG, 1985; SALABARRIA e PINO, 1988), conclui-se que este foi um caso de transmissão transplacentária de Anaplasma marginale. Além da importância econômica e epidemiológica deste tipo de transmissão, Pypers et al. (2011) sugerem que casos agudos de anaplasmose congênita sejam submetidos a investigações adicionais em relação a fatores imunossupressivos, tais como a infecção pelo BVDV, que possam estar afetando o rebanho como um todo e causando outros tipos de prejuízos.

\section{CONCLUSÃO}

O presente relato de caso refere-se ao quadro agudo da anaplasmose bovina transmitida por via transplacentária. Suspeita-se que casos semelhantes não sejam raros, porém pouco descritos devido à falta de investigação, que se torna mais dificultosa quando se considera a ocorrência da enfermidade a campo, muitas vezes em grandes criações extensivas, onde o diagnóstico é impossível ou inviável. Assim, ressalta-se a importância do controle da transmissão do Anaplasma marginale em bovinos e, neste caso, a ênfase que deve ser dada às fêmeas gestantes pela possibilidade de abortos, de nascimento de animais portadores assintomáticos que servirão como reservatório e de bezerros com a forma aguda da doença que, além de difícil diagnóstico, possui tratamento trabalhoso, caro e pouco efetivo. 


\section{REFERÊNCIAS}

AÑEZ-ROJAS, N. et al. Detección de transmisión transplacentaria de Anaplasma marginale en bovinos asintomáticos. Revista Científica, v. 20 n. 4, p. 377-382, 2010.

AUBRY, P.; GEALE, D. W. A review of bovine anaplasmosis. Transboundary and Emerging Diseases, v. 58, p. 1-30, 2011.

BENESI, F. J. et al. Relato de um caso de transmissão transplacentária de anaplasmose bovina. Observações clínico-laboratoriais. Revista Brasileira de Ciência Veterinária, v. 6, n. 30, p. 175-176, 1999.

BIRD, J. E. Neonatal anaplasmosis in a calf. Journal of the South African Veterinary Association, v. 44, n. 1, p. 69-70, 1973.

CORREA, W. M.; CORREA, C. N. M.; GOTTSCHALK, A. F. Bovine abortion associated with Anaplasma marginale. Canadian Journal of Comparative Medicine, v. 42, p. 227-228, 1978.

FOWLER, D.; SWIFT, B. Abortion in cow inoculated with Anaplasma marginale. Theriogenology, v. 4, p. 59-67, 1975.

GONÇALVES, R. C. et al. Anaplasmose neonatal em bezerro. Veterinária Notícias, v. 11, n. 1, p. 95-98, 2005.

GRAU, H. E. G. Transmissão transplacentária de Anaplasma marginale (THEILER, 1910) em bovinos do Rio Grande do Sul. 2006. 54 f. Dissertação (Mestrado em Parasitologia) - Instituto de Biologia, Universidade Federal de Pelotas, Pelotas, 2006.

KESSLER, R.H. Considerações sobre a transmissão de Anaplasma marginale. Pesquisa Veterinária Brasileira, Rio de Janeiro, v. 4, n. 21, p. 177-179, 2001.

KOCAN, K. M. et al. 2003: Antigens and alternatives for control of Anaplasma marginale infection in cattle. Clinical Microbiology Reviews, v. 16, n. 4, p. 698-712, 2003.

LAUS, J. L. et al. Uveíte por anaplasmose em bezerro da raça holandesa. Arquivo Brasileiro de Medicina Veterinária e Zootecnia, v. 58, n. 6, p. 1232-1235, 2006.

NORTON, J. M.; PARKER, R. J.; FORBES-FAULKNER, J. C. Neonatal anaplasmosis in a calf. Australian Veterinary Journal, v. 60, n.11, p. 348, 1983.

PAINE, G. D.; MILLER, A. S. Anaplasmosis in a newborn calf. Veterinary Recovery, v. 100, p. 58, 1977.

PASSOS, L. M. F.; LIMA, J. D. Diagnóstico de anaplasmose bovina congênita em Minas Gerais. Arquivo Brasileiro de Medicina Veterinária e Zootecnia, v. 36, p. 243-244, 1984.

POTGIETER, F. T.; VAN RENSBURG, L. The persistente of colostral Anaplasma marginale antibodies and incidence of in utero transmission of Anaplasma infections in calves under laboratory conditions. The Onderstepoort Journal of Veterinary Research, v. 54, n. 4, p. 557-560, 1987.

PYPERS, A. R.; HOLM, D. E.; WILLIAMS, J. H. Fatal congenital anaplasmosis associated with bovine viral diarrhoea virus (BVDV) infection in a crossbred calf. Journal of the South African Veterinary Association, v. 82, n. 3, p. 179-182, 2011.

RADOSTITS, O. M.. et al. Veterinary Medicine: a textbook of the diseases of cattle, horses, sheep, pigs and goats. $10^{\text {th }}$ ed. New York: Saunders Elsevier, 2007. 2065 p. 
RIBEIRO, M. F. B. et al. Transmissão congênita da anaplasmose bovina. Arquivo Brasileiro de Medicina Veterinária e Zootecnia, v. 47, n. 3, p. 297-304, 1995.

SALABERRIA, F. F.; PINO, R. Transmisión vertical de Anaplasma marginale en bovinos afectados durante el período final de la gestación. Revista Cubana de Ciencias Veterinarias, v. 19, n. 3, p.179$182,1988$.

SWIFT, B. L.; PAUMER, R. J. Vertical transmission of Anaplasma marginale in cattle. Theriogenology, v. 10, p. 515-519, 1976.

SWIFT, B. L.; PAUMER, R. J. Bovine fetal anoxia observed in pregnant beef heifers experimentally inoculated with Anaplasma marginale. Theriogenology, v. 10, p. 395-403, 1978.

TRUEBLOOD, M. S.; SWIFT, B. L.; BEAR, P. D. Bovine fetal response to Anaplasma marginale. American Journal of Veterinary Research, v. 32, n. 7, p. 1089-1090, 1971.

VALEIRÓN, C. R.; ASO, P. M.; CORONADO, A. Prevalencia de Anaplasma marginale y anticuerpos especificos en becerros neonatos. Acta Científica Venezolana, v. 54, n. 2, p. 121-126, 2003.

WANDERA, J. G.; MUNYUA, W. K. Severe anaplasmosis in a 4-day old calf. Bulletin of Epizootic Disease in Africa, v. 19, n. 3, p. 219-221, 1971.

ZAUGG, J. L.; KUTTLER, K. L. Bovine anaplasmosis: in utero transmission and the immunologic significance of ingested colostral antibodies. American Journal of Veterinary Research, v. 45, n. 3, p. 440-443, 1984.

ZAUGG, J. L. Bovine anaplasmosis: transplacental transmission as it relates to stage of gestation. American Journal of Veterinary Research, v. 46, n. 3, p. 570-572, 1985. 
